\title{
Expansive open-door laminoplasty secured with titanium miniplates is a good surgical method for multiple-level cervical stenosis
}

Kuang-Ting Yeh ${ }^{1,2 \dagger}$, Tzai-Chiu Yu ${ }^{2,3+}$, Ing-Ho Chen ${ }^{2,3}$, Cheng-Huan Peng ${ }^{2}$, Kuan-Lin Liu² ${ }^{2}$ Ru-Ping Lee ${ }^{1 *+}$ and Wen-Tien $\mathrm{Wu}^{1,2,3^{*}+}$

\begin{abstract}
Background: Laminoplasty is an effective procedure for treating cervical spondylotic myelopathy (CSM). Little information is available regarding the surgical outcomes of expansive open-door laminoplasty (EOLP) when securing with titanium miniplates without bone grafting. This study is aimed to elucidate the efficacy of and problems associated with EOLP secured with titanium miniplates without bone grafting, thereby enhancing future surgical outcomes.

Methods: This is a retrospective study. The study participants comprised 104 patients who underwent cervical EOLP secured with titanium miniplates without bone graft for CSM treatment between August 2005 and March 2011. The clinical results were evaluated based on the Japanese Orthopedic Association (JOA) and Nurick scores. The radiographic outcomes were determined based on plain film and magnetic resonance imaging findings, which were assessed and compared.

Results: Lateral cervical spine X-rays exhibited improvement in the Pavlov ratio of the spinal canal at 1 day postoperation, and this ratio did not change at 1 year postoperation. The mean cervical curvature from C2 to C7 decreased $0.21^{\circ} \pm 10.09^{\circ}$ and the mean cervical range of motion was deteriorated by $35 \%$ at 12 months $(P<0.05)$. The Nurick score improved from $3.19 \pm 1.06$ to $0.92 \pm 1.32(P<0.05)$. The mean JOA recovery rate was $75 \% \pm 21.1 \%$ at 1 year. The mean level of postoperative neck pain at 3 months was $3.09 \pm 2.31$, as determined using the visual analogue scale (VAS). Increased age, concomitant thoracolumbar stenosis, depression disorder, and preexisting myelomalacia negatively affected the JOA recovery rate $(P<0.05)$. A decreased preoperative Nurick score and superior sensory function in the upper extremities were powerful predictors of an enhanced JOA recovery rate. The postoperative complications involved hematoma formation 0.9\%, reversible C5 nerve palsy 2.8\%, and moderate to severe neck pain (VAS $\geq 4$ ) 42\%. No cases of lamina closure or collapse were observed.

Conclusion: EOLP secured with titanium miniplates without bone grafting is a safe and effective surgical method for treating most patients with CSM.
\end{abstract}

Keywords: Open-door laminoplasty, Cervical spondylotic myelopathy (CSM), Titanium miniplate

\footnotetext{
*Correspondence: fish@mail.tcu.edu.tw; wentien2003@yahoo.com.tw

${ }^{\dagger}$ Equal contributors

${ }^{1}$ Institute of Medical Sciences, Tzu Chi University, No. 701, Zhongyang Rd.,

Sec. 3, Hualien 97004, Taiwan

2Department of Orthopedics, Hualien Tzu Chi Hospital, Buddhist Tzu Chi

Medical Foundation, Hualien 970, Taiwan

Full list of author information is available at the end of the article
}

\section{Biomed Central}

(c) 2014 Yeh et al.; licensee BioMed Central Ltd. This is an Open Access article distributed under the terms of the Creative Commons Attribution License (http://creativecommons.org/licenses/by/2.0), which permits unrestricted use, distribution, and reproduction in any medium, provided the original work is properly credited. The Creative Commons Public Domain Dedication waiver (http://creativecommons.org/publicdomain/zero/1.0/) applies to the data made available in this article, unless otherwise stated. 


\section{Background and introduction}

Cervical spondylosis is an age-related degenerative change in the spine. Radiographic evidence of cervical spondylosis can be observed in more than $85 \%$ of those greater than 60 years old [1]. In cervical spondylosis, herniated discs; osteophytes; arthritic facet joints; buckled, thickened, or ossified ligamentum flavum; and hypertrophy or ossification of the posterior longitudinal ligament may all cause multilevel cervical stenosis, resulting in spinal cord compression. Chronic compression of the cervical spinal cord causes the clinical syndrome of cervical spondylotic myelopathy (CSM) [2,3]. In certain patients who exhibit developmental stenosis of the cervical spine, myelopathy may occur early in life, particularly after hyperextension injuries [4].

Patients who experience progressive, long-standing, or severe myelopathy are candidates for surgical decompression of the spinal cord [2,5-7]. The options decompressing multilevel stenosis involve anterior or posterior approaches. The factors influencing the operative approach are the location of the cord compression, number of levels involved, sagittal alignment, instability, associated axial neck pain, and risk factors for pseudarthrosis $[7,8]$. Anterior cervical discectomy with fusion (ACDF), anterior cervical corpectomy with fusion (ACCF), and a combination of both are major anterior approaches that directly eliminate the anterior compression. The posterior options are laminectomy without fusion, laminectomy with instrumented fusion, and laminoplasty. The posterior approach relies on the decompression by both the direct removal of offending posterior structures and indirect posterior translation of the spinal cord; thus, patients should undergo maintenance of lordosis or correctable kyphosis to permit adequate indirect decompression [5]. Laminoplasty is superior to laminectomy without fusion because it decreases perineural adhesion and late kyphosis. Compared with ACDF, ACCF, or laminectomy involving instrumented fusion, laminoplasty preserves motion segments and prevents fusion-related complications, including bone graft dislodgement, pseudarthrosis, and adjacent segment disease [5,9].

Several types of laminoplasty exist such as Z plasty, open-door laminoplasty, and French-door laminoplasty with variable modifications $[7,10]$. Laminar $\mathrm{Z}$ plasty was devised by Hattori in 1971, reported by Oyama in 1973 [11], and subsequently modified by Tomimura and Watanabe in 1984 and 1987, respectively. Because of their complexity, these techniques were not popular [9].

Expansive open-door laminoplasty (EOLP) was developed by Hirabayashi in 1977; which was fixed with suture material between a hinge-side facet capsule and opened laminae. French-door laminoplasty was first documented by Kurokawa in 1982. Both EOLP and French-door laminoplasty became popular, and multiple subtypes of these operations were developed [9]. Biomechanical studies have demonstrated that the range of motion (ROM) and stability of the cervical spine did not change immediately after expansive laminoplasty $[12,13]$; however, in one study, the ROM significantly decreased after 6 months. Herkowitz determined that EOLP yields a decompression effect equivalent to that of laminectomy or anterior decompression with fusion $[14,15]$. Moreover, previous reports on long-term surgical outcomes have indicated the usefulness of conducting laminoplasty to treat patients with CSM [16]. However, complications have been reported shortly after surgery, and $30 \%-60 \%$ of patients exhibited postoperative neck pain $[17,18], 0 \%-30 \%$ (4.7\%) exhibited C5 palsy $[19,20]$ and $34 \%$ exhibited lamina closure [21,22], thereby compromising the surgical results. In 1996, O'Brien et al. reported a method involving maxillofacial miniplates and screws for securing the laminae in their opened positions [23]. This design provides primary resistance against closure of the laminae. Conducting EOLP by using miniplates and screw fixation remains a popular technique for treating multilevel CSM; however, few clinical reports have been conducted regarding this method.

Various methods can be employed to open the laminae and fix them to prevent reclosure. When conducting EOLP, we use the scalp clip applier as a special laminae opening tool and fix the opened laminae by using self-bent titanium miniplates. In this study, we present the surgical outcome of treating 104 patients with multilevel CSM by using EOLP secured with titanium miniplates without bone grafting.

\section{Materials and methods \\ Study population}

This study involved a retrospective design. The participants comprised 104 consecutive patients who underwent EOLP secured with titanium miniplates to treat CSM between August 2005 and March 2011. Clinical diagnoses were made by conducting physical examinations and using plain radiography and magnetic resonance imaging (MRI). All patients who met the following criteria were included in the study: (1) bilateral hand clumsiness and an unsteady gait; (2) positive myelopathic signs and symptoms, such as increased tendon reflexes in the extremities, clumsiness in the hands, and impaired toe-to-heel tandem gait; and (3) C3-C7 stenosis without segmental instability or kyphosis. Those who exhibited a history of cervical spinal surgery or presented with myelopathy because of spinal cord tumors or injuries were excluded. Demographic data and comorbidities were collected and recorded.

The severity of myelopathy was rated using Japanese Orthopedic Association (JOA) [24,25] and Nurick scores [26]. The surgical outcomes were further evaluated using the JOA recovery rate $[24,25]$. The cervical curvature, ROM, and Pavlov ratio [27] (i.e., the canal-body ratio) were determined based on the plain films and the compressive 
ratios with or without preoperative myelomalacia were determined based on MRI (Figure 1); these factors all affected the postoperative outcomes [28,29]. Patient conditions (e.g., age and gender) and comorbidities, such as diabetes mellitus (DM) and concomitant thoracolumbar (TL) stenosis, could also influence the evaluations of the surgical results [30]. Computed tomography (CT) scans and MRI studies were used to observe the stability at fixation sites and the postoperative decompression of the spinal cord.

We determined the Pavlov ratio at the C5 level based on neutral lateral X-rays. The cervical curvature was determined based on the lordotic angle, which was measured between the lower end plate of $\mathrm{C} 2$ and upper end plate of $\mathrm{C} 7$ in neutral lateral X-rays. The cervical ROM was defined as the difference in lordotic angle; from the lower end plate of $\mathrm{C} 2$ to the upper end plate of $\mathrm{C} 7$ between the extension and flexion lateral X-rays. The sagittal and axial compressive ratios from the preoperative MRI studies were estimated and recorded. This study was approved by the Research Ethics Committee of Hualien Tzu Chi Hospital, Buddhist Tzu Chi Medical Foundation (IRB101-100).

\section{Surgical procedures}

The technique used in this study was modified from techniques that have been used in previous studies [23,31] and is detailed as follows. The posterior approach was made from the $\mathrm{C} 2$ to $\mathrm{T} 1$ levels by using a midline longitudinal incision. The paraspinal muscles were subperiosteally dissected from the spinous processes to the lateral masses. The muscular insertions at the spinous process of $\mathrm{C} 2$ were protected from division. The intervals between the junction of the lamina and the facet joints were bilaterally developed from $\mathrm{C} 3$ to $\mathrm{C} 7$. On the hinge side, the outer cortex was removed using a 2 -mm high-speed cutting burr to make a trough.

On the open side, the 3-mm high-speed cutting burr was used to clean the outer cortex and cancellous bone. The remaining inner cortex was removed using a 1- or 1.5-mm Kerrison punch. The facet joints on both sides were protected from violation. The ligamentum flavum was divided between the $\mathrm{C} 2$ and $\mathrm{C} 3$ and $\mathrm{C} 7$ and $\mathrm{T} 1$ vertebrae. The laminae from $\mathrm{C} 3$ to $\mathrm{C} 7$ were then opened by a scalp clip applier (Mizuho Ika, Tokyo, Japan) as a spreader, followed by sequentially dividing the underlying ligamentum flavum on the opening side (Figure 2). Each lamina was maintained open and fixed with a 5-hole miniplate that was cut from a long, straight miniplate (Synthes $2.0 \mathrm{~mm}$ titanium miniplate 20 holes, adaption, Switzerland) and bent into the shape of wide-angled $\mathrm{Z}$ to fit both the cut edge of lamina and the lateral mass (Figure 3A). The well-bent miniplates were securely fixed with one miniscrew at each site at the $\mathrm{C} 3$ to $\mathrm{C} 7$ levels (Figure 3B,C). A rigid cervical collar was subsequently required for 3 months, and the patients
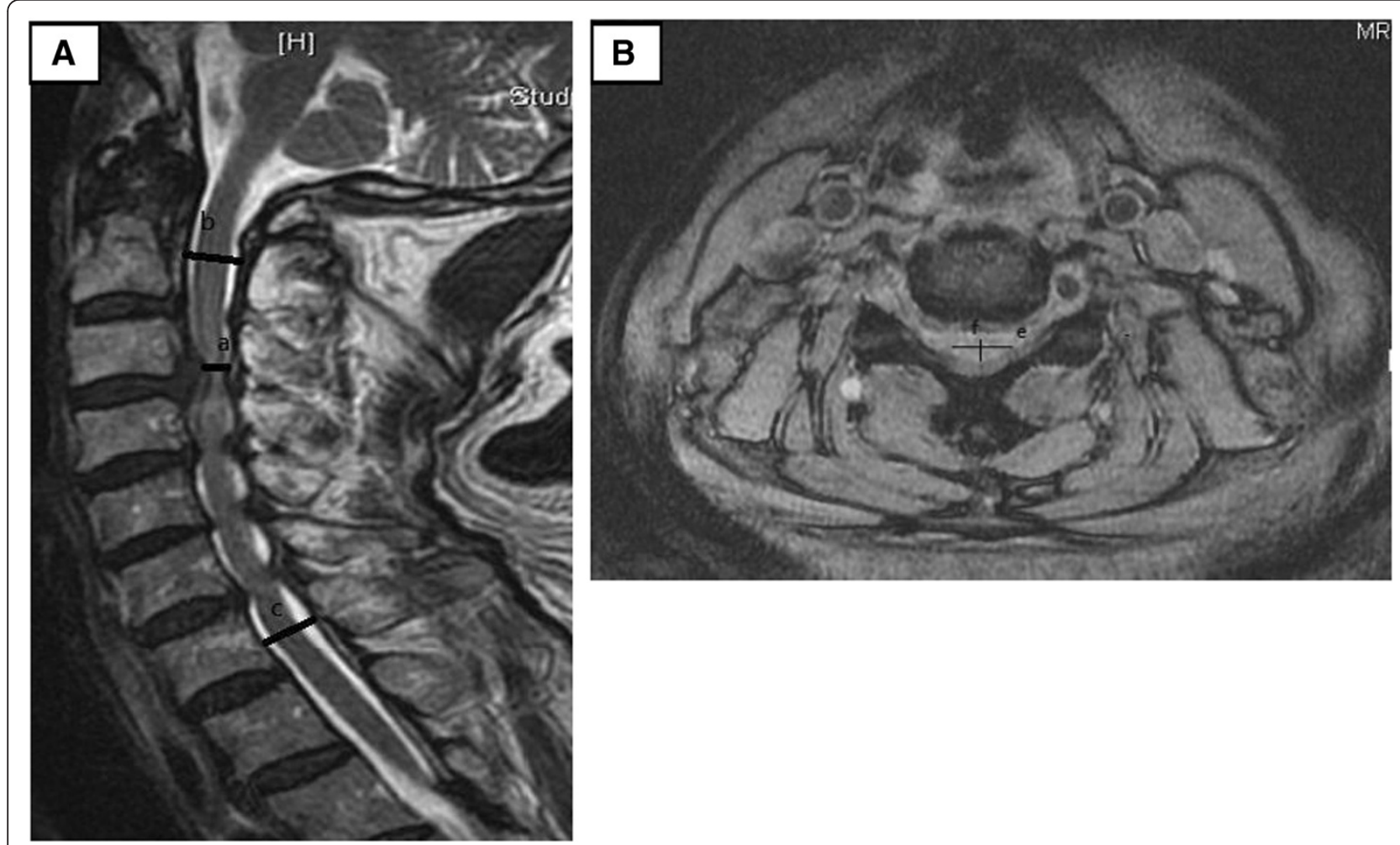

Figure 1 T2 MRI image of cervical spine. (A) Sagittal view. Sagittal compressive ratio $=a \times 2 /(b+c)$. (B) Axial view. Axial compressive ratio $=f / e$. 

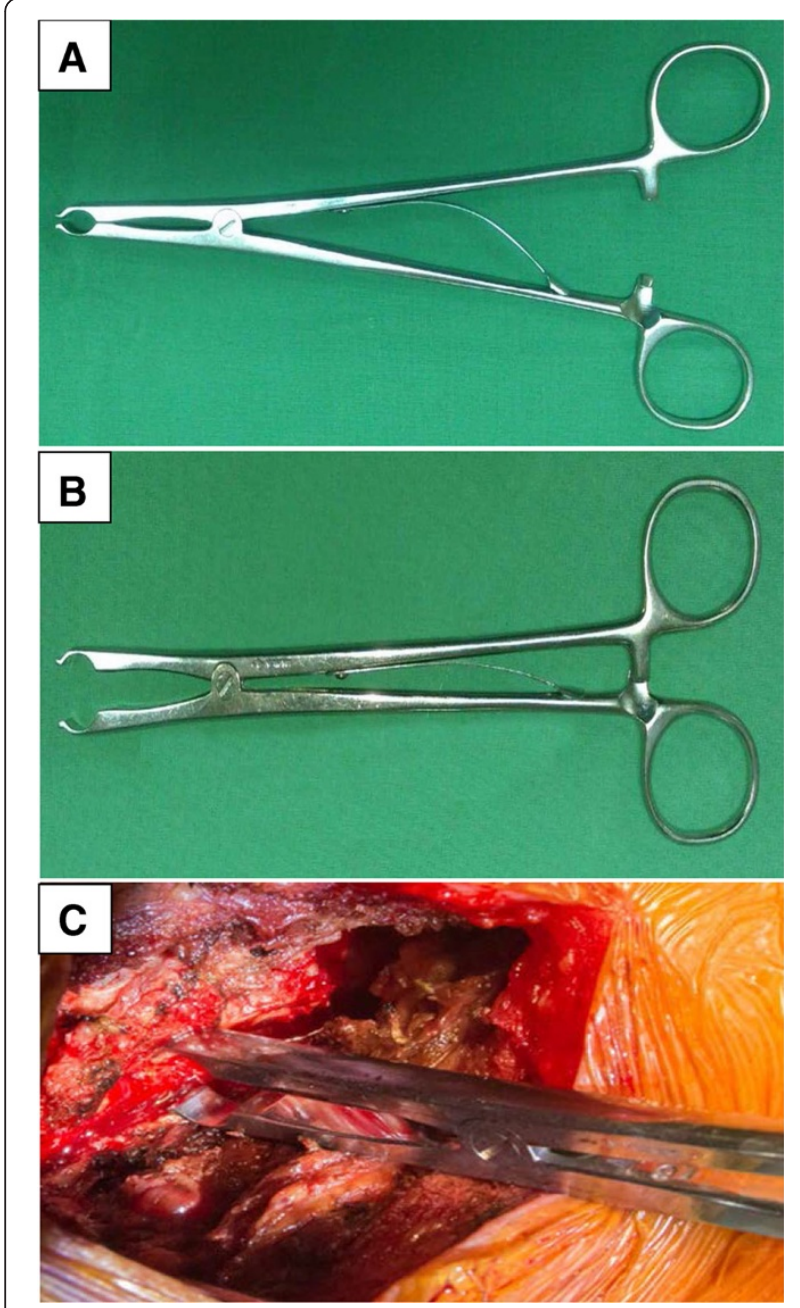

Figure 2 Scalp clip applier (A and B) used as a spreader (C) for opening burred gutters of laminae.

were taught to perform neck extension exercises while protected by the collar.

\section{Outcome evaluation \\ Radiographic data}

Neutral lateral cervical X-rays were captured preoperatively and at Day 0, 6 weeks, 3 months, 6 months, 1 year, and annually postoperation (Figure 4A,B). Dynamic X-rays were captured preoperatively and at 3 months, 6 months, and 1 year postoperation. CT scans were performed at 6 months postoperation and used to measure the union on the hinge side; a strong union was defined as cortical continuity at all axial cuts of the opened levels. MRI screenings were arranged at 12 months postoperation to evaluate the spinal cord decompression conditions. The cervical curvature, ROM, Pavlov ratio at the C5 level, and sagittal and axial compressive ratios were independently measured by two orthopedic doctors.

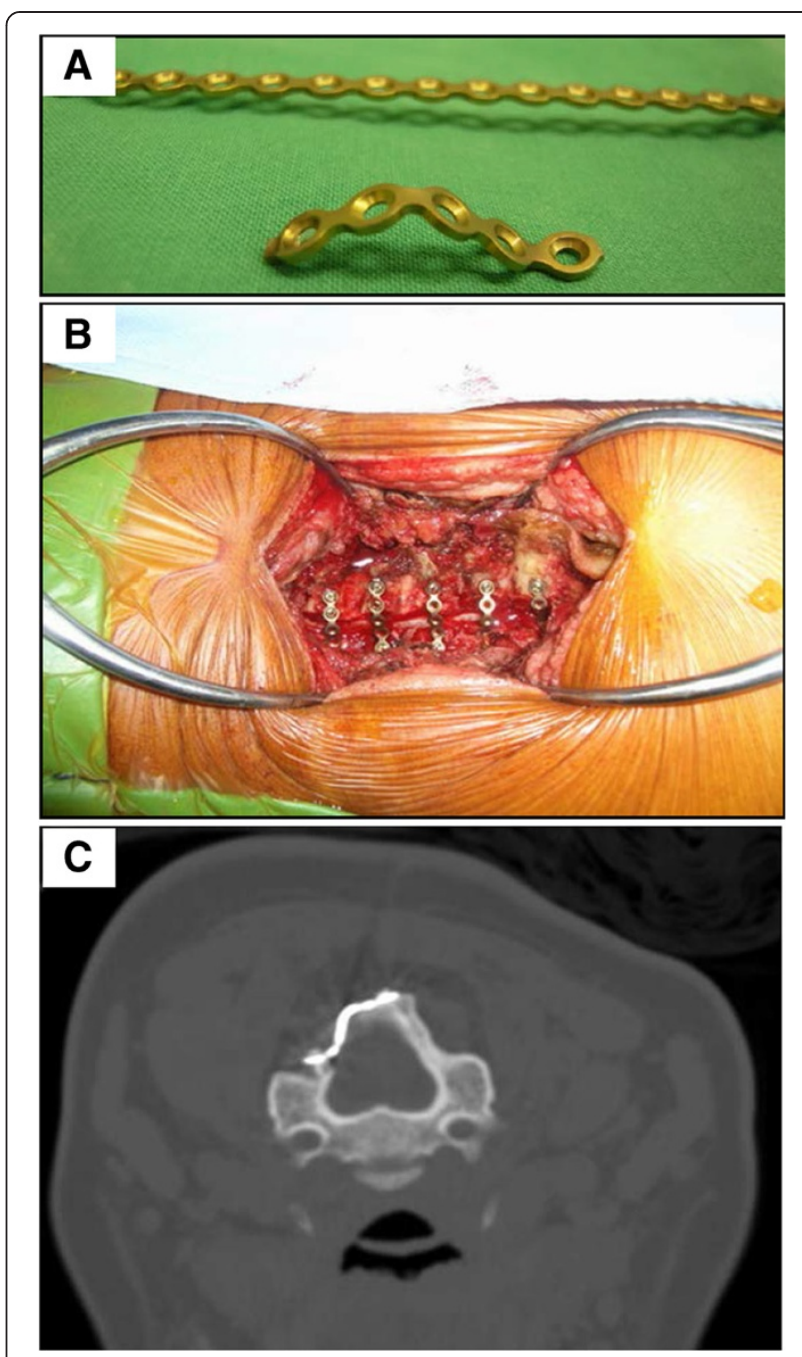

Figure 3 Applying titanium miniplates. (A) The plate was cut into pieces and they were bent into a wide-angled $Z$ shape. (B) The open side was secured with five pieces of bent miniplates. The spinal cord was decompressed and inflated. (C) Each titanium miniplate was bent and applied to both the elevated laminae and lateral mass by fixing one miniscrew at each side.

\section{Clinical data}

The neurological status was evaluated using the JOA $[24,25]$ and Nurick scores [26] preoperatively and at 12 months postoperation. Postoperative neck pain was evaluated using a 10-point visual analogue scale (VAS) at 2 weeks and 3 months postoperation. The JOA recovery rate at postoperative 12 months, which represents the degree of normalization after surgery, was calculated using the Hirabayashi formula: (Postoperative score Preoperative score $) \times 100 /(17$ - Preoperative score $)[24,25]$. We also recorded any postoperative complications.

\section{Statistical analysis}

Data were presented as means \pm standard deviation (SD). A paired $t$ test was conducted to statistically analyze the 

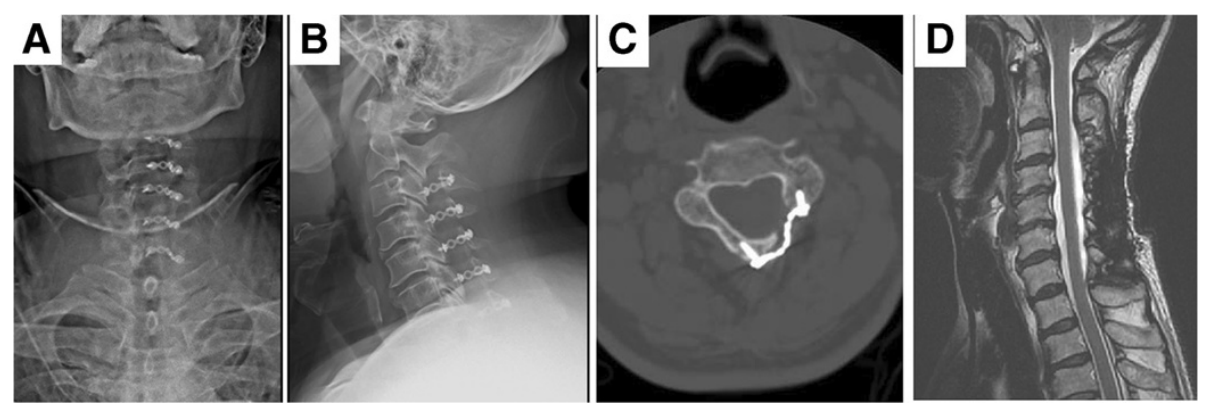

Figure 4 Postoperative radiographic follow-up. (A) AP view and (B) lateral view at postoperative 3 months. (C) CT scan at postoperative 6 months revealed well-positioned miniplate and screws and bone healing of hinge side. (D) MRI study at postoperative 12 months showed patent spinal cord without compression.

difference between the preoperative and postoperative scores. A stepwise regression analysis was used to correlate the preoperative condition to the JOA recovery rate. A $P$ value of $<0.05$ was considered statistically significant.

\section{Results}

The participants comprised 67 men and 37 women, whose ages were $27-90$ years old (mean $=60.13 \pm 11.89$ years old). The mean myelopathic symptom duration period was $14.86 \pm 6.46$ months. The mean period of symptom aggravation was $2.82 \pm 1.1$ months. All procedures were performed by one surgeon. The mean operation time was $122 \mathrm{~min}$, and the mean blood loss was $245 \mathrm{ml}$. The mean postoperative follow-up period was $25.2 \pm 3.2$ months. Because no significant differences were observed between the surgical outcomes at 12 and 24 months postoperation, only the data until month 12 are presented herein.

\section{Radiologic evaluation}

No hardware failure was observed during the follow-up period. The mean cervical curvature values before the operation and at 3 months postoperation were $9.7^{\circ} \pm 8.5^{\circ}$ and $7.0^{\circ} \pm 9.7^{\circ}$, respectively (Table 1 ). The lordotic angle was

Table 1 Preoperative/Postoperative radiographic status and their correlation to recovery rate $(N=104)$

\begin{tabular}{|c|c|c|c|}
\hline Items & $\begin{array}{c}\text { Curvature } \\
\text { (Cobb angle) }\end{array}$ & Pavlov ratio & ROM \\
\hline Preop & $9.7 \pm 8.5$ & $0.66 \pm 0.06$ & $24.6 \pm 12.2$ \\
\hline POD 1D & - & $1.13 \pm 0.10$ & - \\
\hline POD 3M & $7.1 \pm 9.7$ & - & $14.4 \pm 7.2$ \\
\hline POD 12M & $9.5 \pm 18.2$ & $1.12 \pm 0.10$ & $16.0 \pm 7.5$ \\
\hline POD 1D-Preop ${ }^{a}$ & - & $-112.44^{*}$ & - \\
\hline POD 3M-Preop ${ }^{a}$ & $2.70^{*}$ & - & $15.62^{*}$ \\
\hline POD 12M-Preop ${ }^{a}$ & 0.12 & $-112.97^{*}$ & $14.57^{*}$ \\
\hline Preop vs. RR ${ }^{b}$ & -0.10 & 0.04 & $0.06^{*}$ \\
\hline
\end{tabular}

${ }^{a} r$ value; ${ }^{b} t$ value; ${ }^{*} P<0.05$. restored to $9.5^{\circ} \pm 18.9^{\circ}(P<0.05)$ at 12 months postoperation. The mean Pavlov ratios (i.e., canal-body ratio) at the C5 level measured from X-rays of the lateral cervical spine were $0.66 \pm 0.05$ before the operation, $1.13 \pm 0.10$ immediately following the operation, and $1.12 \pm 0.10$ at 12 months postoperation, indicating significant improvement immediately following the operation $(P<0.05)$ and no collapse or laminae closure at 12 months postoperation (Table 1). The mean ROM values were $24.6 \pm 12.2$ degrees before the operation, $14.4^{\circ} \pm 7.2^{\circ}$ at 3 months postoperation, and $15.99^{\circ} \pm$ $7.49^{\circ}$ at 1 year postoperation (Table 1 ). The loss of ROM was approximately $35 \%$ at 1 year postoperation $(P<0.05)$. $\mathrm{CT}$ scans at 6 months postoperation demonstrated satisfactory stability levels and bony fusion over the hinge sides (Figure 4C). The preoperative mean sagittal compressive ratio and axial compressive ratio were $0.56 \pm 0.06$ and $0.36 \pm$ 0.03 , respectively. Preoperative myelomalacia was observed in 39 patients (37.5\%), and significantly and negatively affected the JOA recovery rate $(P<0.05$, Table 2$)$. MRI screening at 1 year postoperation revealed patent spinal cord and substantial enlargement of the spinal canal (Figure 4D).

\section{Clinical evaluation}

Increased age, concomitant TL stenosis, and depression disorder negatively affected the JOA recovery rate $(P<0.05$, Table 3$)$. The Nurick scores increased from $3.2 \pm 1.0$ to $0.9 \pm 1.3$, and the JOA scores increased from $10.3 \pm 2.9$ to $15.0 \pm 2.1$, attaining significant improvement $(P<0.05)$. The VAS for postoperative neck pain at 2 weeks and 3 months was $6.4 \pm 1.2$ and $2.3 \pm 2.2$, respectively (Table 4). The JOA recovery rate was $75 \% \pm 21.1 \%$ among the study patients. The results of a regression analysis indicated that preoperative Nurick scores and the sensory function in the upper extremities section of the JOA score were strong predictors of the JOA recovery rate (Table 5).

\section{Complications}

No mortality occurred after operation. One patient experienced a dural tear that required lumbar drain shunting. 
Table 2 The correlation between preoperative condition and JOA score $(N=104)$

\begin{tabular}{|c|c|c|c|c|c|c|c|c|c|}
\hline Items & $\begin{array}{l}\text { Sample } \\
\text { size } n(\%)\end{array}$ & $\begin{array}{l}\text { Upper extremities } \\
\text { motor function }\end{array}$ & $\begin{array}{l}\text { Lower extremities } \\
\text { motor function }\end{array}$ & $\begin{array}{l}\text { Upper extremities } \\
\text { sensory function }\end{array}$ & $\begin{array}{l}\text { Lower extremities } \\
\text { sensory function }\end{array}$ & $\begin{array}{l}\text { Trunk sensory } \\
\text { function }\end{array}$ & $\begin{array}{l}\text { Bladder } \\
\text { function }\end{array}$ & JOA score & $\begin{array}{l}\text { Recovery } \\
\text { rate }\end{array}$ \\
\hline Sagittal compressive ratio $^{a}$ & $0.56 \pm 0.06$ & 0.06 & -0.01 & 0.01 & -0.04 & -0.05 & -0.14 & -0.06 & 0.05 \\
\hline AP compressive ratio ${ }^{a}$ & $0.36 \pm 0.03$ & 0.06 & -0.01 & 0.01 & -0.04 & -0.05 & -0.14 & -0.06 & 0.05 \\
\hline Myelomalacia $^{\mathrm{b}}$ & & -0.62 & 0.67 & -0.05 & 1.21 & $2.36^{*}$ & -0.08 & 0.67 & $-2.10^{*}$ \\
\hline No & $65(62.5)$ & $1.49 \pm 0.90$ & $1.46 \pm 0.96$ & $0.88 \pm 0.45$ & $0.42 \pm 0.49$ & $0.09 \pm 0.29$ & $0.22 \pm 0.62$ & $4.60 \pm 1.99$ & $0.78 \pm 0.18$ \\
\hline Yes & $39(37.5)$ & $1.38 \pm 0.74$ & $1.59 \pm 0.88$ & $0.87 \pm 0.41$ & $0.54 \pm 0.51$ & $0.31 \pm 0.52$ & $0.21 \pm 0.57$ & $4.87 \pm 2.02$ & $0.69 \pm 0.25$ \\
\hline
\end{tabular}


Table 3 Demographic and comorbidity data and their correlation with JOA score $(N=104)$

\begin{tabular}{|c|c|c|c|c|c|c|c|c|c|}
\hline Items & Sample size, $n$ & $\begin{array}{l}\text { Upper extremities } \\
\text { motor function }\end{array}$ & $\begin{array}{l}\text { Lower extremities } \\
\text { motor function }\end{array}$ & $\begin{array}{l}\text { Upper extremities } \\
\text { sensory function }\end{array}$ & $\begin{array}{l}\text { Lower extremities } \\
\text { sensory function }\end{array}$ & $\begin{array}{l}\text { Trunk sensory } \\
\text { function }\end{array}$ & $\begin{array}{l}\text { Bladder } \\
\text { function }\end{array}$ & JOA score & $\begin{array}{l}\text { JOA Recovery } \\
\text { rate }\end{array}$ \\
\hline$\overline{\mathrm{Age}^{\mathrm{a}}}$ & $60.13 \pm 11.89$ & 0.04 & 0.01 & 0.01 & 0.13 & -0.11 & 0.11 & 0.10 & $-0.25^{*}$ \\
\hline Gender $^{\mathrm{b}}$ & & -0.55 & 0.62 & 0.17 & 0.43 & -0.80 & 0.28 & -0.51 & -0.02 \\
\hline Male & 67 & $1.42 \pm 0.80$ & $1.55 \pm 0.87$ & $0.88 \pm 0.44$ & $0.48 \pm 0.50$ & $0.15 \pm 0.35$ & $0.22 \pm 0.62$ & $4.63 \pm 1.96$ & $0.75 \pm 0.21$ \\
\hline Female & 37 & $1.51 \pm 0.93$ & $1.43 \pm 1.04$ & $0.48 \pm 0.50$ & $0.43 \pm 0.50$ & $0.22 \pm 0.47$ & $0.19 \pm 0.56$ & $4.84 \pm 2.07$ & $0.75 \pm 0.20$ \\
\hline Smoke & & 0.40 & 1.30 & 1.20 & -0.51 & 0.27 & -0.08 & 0.94 & 0.52 \\
\hline No & 89 & $1.44 \pm 0.86$ & $1.46 \pm 0.96$ & $0.85 \pm 0.44$ & $0.47 \pm 0.50$ & $0.17 \pm 0.40$ & $0.21 \pm 0.63$ & $4.65 \pm 2.10$ & $0.74 \pm 0.21$ \\
\hline Yes & 15 & $1.53 \pm 0.74$ & $1.80 \pm 0.67$ & $1.00 \pm 0.37$ & $0.40 \pm 0.50$ & $0.20 \pm 0.41$ & $0.20 \pm 0.41$ & $5.00 \pm 1.13$ & $0.77 \pm 0.21$ \\
\hline Depression ${ }^{\mathrm{b}}$ & & -1.95 & -0.65 & -0.11 & -0.17 & $-4.38^{*}$ & $-3.59^{*}$ & -1.97 & $-2.73^{*}$ \\
\hline No & 97 & $0.86 \pm 0.69$ & $1.53 \pm 0.95$ & $0.88 \pm 0.44$ & $0.46 \pm 0.50$ & $0.19 \pm 0.42$ & $0.23 \pm 0.62$ & $4.80 \pm 2.00$ & $0.76 \pm 0.20$ \\
\hline Yes & 7 & $1.49 \pm 0.84$ & $1.29 \pm 0.48$ & $0.86 \pm 0.37$ & $0.43 \pm 0.53$ & $0.00 \pm 0.00$ & $0.00 \pm 0.00$ & $3.29 \pm 1.25$ & $0.54 \pm 0.26$ \\
\hline $\mathrm{DM}^{\mathrm{b}}$ & & 1.10 & 0.07 & -1.34 & 0.63 & 0.82 & -1.49 & 0.27 & -0.10 \\
\hline No & 83 & $1.41 \pm 0.88$ & $1.51 \pm 0.90$ & $0.90 \pm 0.43$ & $0.45 \pm 0.50$ & $0.16 \pm 0.36$ & $0.24 \pm 0.65$ & $4.67 \pm 2.00$ & $0.75 \pm 0.22$ \\
\hline Yes & 21 & $1.62 \pm 0.66$ & $1.52 \pm 1.07$ & $0.76 \pm 0.43$ & $0.52 \pm 0.51$ & $0.24 \pm 0.53$ & $0.10 \pm 0.30$ & $4.81 \pm 2.01$ & $0.74 \pm 0.16$ \\
\hline$C A D^{b}$ & & 1.29 & 1.59 & -0.61 & 0.65 & -0.57 & 0.44 & 1.17 & 1.10 \\
\hline No & 81 & $1.40 \pm 0.84$ & $1.43 \pm 0.93$ & $0.89 \pm 0.44$ & $0.44 \pm 0.50$ & $0.19 \pm 0.39$ & $0.20 \pm 0.57$ & $4.58 \pm 1.87$ & $0.74 \pm 0.21$ \\
\hline Yes & 23 & $1.65 \pm 0.83$ & $1.78 \pm 0.90$ & $0.83 \pm 0.38$ & $0.52 \pm 0.51$ & $0.13 \pm 0.45$ & $0.26 \pm 0.68$ & $5.13 \pm 2.38$ & $0.79 \pm 0.20$ \\
\hline Previous neck trauma ${ }^{b}$ & & -0.62 & -0.18 & 1.28 & -0.24 & 0.94 & -0.10 & -0.29 & 0.34 \\
\hline No & 79 & $1.48 \pm 0.90$ & $1.52 \pm 0.99$ & $0.85 \pm 0.45$ & $0.47 \pm 0.50$ & $0.15 \pm 0.39$ & $0.22 \pm 0.65$ & $4.73 \pm 2.15$ & $0.74 \pm 0.21$ \\
\hline Yes & 25 & $1.36 \pm 0.63$ & $1.48 \pm 0.71$ & $0.96 \pm 0.35$ & $0.44 \pm 0.50$ & $0.24 \pm 0.43$ & $0.20 \pm 0.40$ & $4.60 \pm 1.38$ & $0.76 \pm 0.20$ \\
\hline ConcomitantT-L stenosis ${ }^{\mathrm{b}}$ & & -0.94 & 0.12 & -1.69 & 0.64 & -1.19 & 0.95 & -0.24 & $-2.55^{*}$ \\
\hline No & 62 & $1.52 \pm 0.78$ & $1.50 \pm 0.82$ & $0.94 \pm 0.40$ & $0.44 \pm 0.50$ & $0.21 \pm 0.44$ & $0.16 \pm 0.48$ & $4.74 \pm 1.95$ & $0.79 \pm 0.18$ \\
\hline Yes & 42 & $1.36 \pm 0.93$ & $1.52 \pm 1.08$ & $0.79 \pm 0.47$ & $0.50 \pm 0.50$ & $0.12 \pm 0.32$ & $0.29 \pm 0.74$ & $4.64 \pm 2.07$ & $0.69 \pm 0.23$ \\
\hline
\end{tabular}


Table 4 Preoperative/Postoperative function status and their correlation to recovery rate $(N=104)$

\begin{tabular}{|c|c|c|c|c|c|c|c|}
\hline \multirow[t]{2}{*}{ Items } & \multirow{2}{*}{$\begin{array}{c}\text { Preop } \\
\text { Mean (SD) }\end{array}$} & \multirow{2}{*}{$\begin{array}{c}\text { Postop } \\
\text { Mean (SD) }\end{array}$} & \multirow{2}{*}{$\begin{array}{c}\text { Postop-preop } \\
\text { Mean (SD) }\end{array}$} & \multicolumn{2}{|c|}{ Postop-preop } & \multicolumn{2}{|c|}{ Preop vs. RR } \\
\hline & & & & $t$ & $P$ & $r$ & $P$ \\
\hline Nurick score & $3.2 \pm 1.1$ & $0.9 \pm 1.3$ & $-2.3 \pm 0.9$ & 26.18 & $<0.001$ & -0.50 & $<0.001$ \\
\hline VAS & $5.1 \pm 1.8$ & $2.3 \pm 2.2$ & $-2.9 \pm 2.4$ & 12.38 & $<0.001$ & -0.41 & $<0.001$ \\
\hline JOA score & $10.3 \pm 2.9$ & $15.0 \pm 2.1$ & $4.7 \pm 2.0$ & -24.04 & $<0.001$ & 0.50 & $<0.001$ \\
\hline JOA upper extremities motor function & $2.1 \pm 1.0$ & $3.5 \pm 0.8$ & $1.5 \pm 0.8$ & -17.50 & $<0.001$ & 0.43 & $<0.001$ \\
\hline JOA lower extremities motor function & $1.9 \pm 1.2$ & $3.4 \pm 0.9$ & $1.5 \pm 0.9$ & -16.47 & $<0.001$ & 0.37 & $<0.001$ \\
\hline JOA upper extremities sensory function & $0.6 \pm 0.6$ & $1.4 \pm 0.5$ & $0.9 \pm 0.4$ & -20.57 & $<0.001$ & 0.45 & $<0.001$ \\
\hline JOA lower extremities sensory function & $1.2 \pm 0.7$ & $1.7 \pm 0.5$ & $0.5 \pm 0.5$ & -9.40 & $<0.001$ & 0.22 & 0.026 \\
\hline JOA trunk sensory function & $1.8 \pm 0.5$ & $1.9 \pm 0.2$ & $0.2 \pm 0.4$ & -4.36 & $<0.001$ & -0.03 & 0.784 \\
\hline JOA bladder function & $2.7 \pm 0.7$ & $2.9 \pm 0.2$ & $0.2 \pm 0.6$ & -3.58 & 0.001 & 0.11 & 0.267 \\
\hline
\end{tabular}

$\mathrm{RR}$, recovery rate.

One patient had a postoperative hematoma that required immediate reoperation. Three patients exhibited transient postoperative C5 nerve palsy (MMT score $<3$ ), but were completely recovered at 3 months postoperation. Five exhibited poor wound healing that required a prolonged or second admission for reoperation and antibiotic treatment. No neurological deterioration was noted. At 3 months postoperation, 10 patients had developed kyphosis of the cervical spine according to follow-up X-rays. Moderate to severe neck pain and VAS scores $\geq 4$ were noted in $42 \%$ of patients at 3 months postoperation; however, these patients exhibited strong functional recovery rates.

\section{Discussion}

CSM was proven to result from the narrowing of the normal anteroposterior cervical spinal canal to a critical threshold [13]. The normal cervical aging process, congenital narrowing aggravated by acute trauma and bony malformations were identified as the primary causes of cervical stenosis that result in myelopathy [32]. The prognosis of untreated myelopathy was typically poor and conservative treatment was largely ineffective in ceasing the progression of neurological deterioration [15]. Operations have become a mainstream method of treating. Anterior approaches, (primarily ACDF, ACCF, or a combination of both) could be used to eliminate anterior compression directly and correct kyphotic deformity and instability. These approaches

Table 5 The predictive power of preoperative condition to recovery rate $(N=104)$

\begin{tabular}{lcccc}
\hline Items & R & R square & $\begin{array}{c}\text { R square } \\
\text { change }\end{array}$ & $\begin{array}{c}\text { Sig. } \mathbf{F} \\
\text { change }\end{array}$ \\
\hline Nurick score & 0.50 & 0.25 & 0.25 & 0.00 \\
Upper extremity sensory function & 0.62 & 0.38 & 0.13 & 0.00 \\
T-L spondylosis & 0.66 & 0.43 & 0.06 & 0.00 \\
Depression & 0.68 & 0.46 & 0.03 & 0.03 \\
VAS & 0.70 & 0.49 & 0.02 & 0.04 \\
\hline
\end{tabular}

are reserved for pathology less than or equal to three motion segments. Regarding multilevel CSM in four or more motion segments, posterior procedures are the primary treatment options [5]. Laminectomy, an accepted decompressive procedure for treating multilevel CSM, has been reported to cause an increased incidence of complications, including perineural adhesion, instability, and late kyphosis involving neurological deterioration. Laminectomy with instrumented fusion provides stability and prevents late kyphosis; however, problems related to perineural adhesion and fusion have been reported $[5,33]$. Laminoplasty, through various modifications and improvements, is considered advantageous for expanding the spinal canal and can preserve the posterior structure of the cervical spine in an effort to secure stability and prevent the formation of a postlaminectomy membrane. In addition, numerous studies have reported satisfactory surgical outcomes among patients receiving laminoplasty [34]. Hirabayashi described EOLP based on a modification from O'Brien, and the method of using titanium miniplates to secure the opening of spinal canal has remained a popular surgical procedure $[28,31]$. Customized miniplates have been developed to fix the opened laminae; however, these are expensive and the adaptation can be limited by local anatomy. In this study, we conducted the operations by using self-bent miniplates cut from a long, straight titanium miniplate; using this method is both cheaper and more popular than using customized miniplates. The self-bent miniplates were advantageous because they could be readily applied and shaped and provided effective stability. In our case series, no laminae collapse or implant dislodgement was indicated in the follow-up plain films or CT scans.

In the study of Ratliff, cervical curvature was decreased by $35 \%$ and ROM was decreased by $50 \%$ after laminoplasty [35]. The loss of ROM was progressive and plateaued at 18 months postlaminoplasty [36]. In the biomechanical study of Puttlitz, neck extension-flexion ROM was decreased by 
approximately $25 \%$ at 6 months postlaminoplasty and no obvious kinetic differences were observed between EOLP and French-door laminoplasty [12]. The study suggested that decreased intervertebral motion should be expected and early rehabilitation therapy should be considered. In the current study, significant decreases in cervical curvature and ROM losses were observed at 3 months postoperation. The cervical curvature had almost returned to preoperative levels at 1 year postoperation. However, the ROM was only partially restored. The mean loss of cervical ROM was 35\% at 2 years postoperation. In this study, the reason for the improved cervical curvature and ROM from 3 months to 1 year postoperation was aggressive rehabilitation after removal of the neck collar at 3 months postoperation. Lamina closure has been associated with unsatisfactory clinical outcomes after laminoplasty. It can be defined as a decrease of greater than $10 \%$ in the canal-body ratio (i.e., Pavlov ratio) [21]. In the study of Matsumoto, 34\% of patients receiving open-door laminoplasty without plates or spacers on the open sides developed lamina closure [21]. In the current study, no cases of this complication were observed at 12 months postoperation. Our bent miniplates provided initial resistance and good stability for elevated laminae.

The surgical outcomes and risk factor analyses were primarily assessed using the JOA recovery rate; despite the popularity of this method, it involves certain limitations. Based on the preoperative JOA score, the actual surgical recovery could be distinct among patients who exhibit the same recovery rates. The recovery rate is low among patients who exhibit a low preoperative JOA score, even if they attain the same postoperative scores. Thus, we analyzed the six individual sections of the JOA score to determine how the levels of postoperative improvement and preoperative severity were correlated with the surgical outcome. We also used the Nurick score as a secondary method of assessing postoperative conditions. We determined that sensory and motor deficit in the limbs were highly correlated with the recovery rate, particularly the sensory parts of the upper extremities. We proved that the Nurick score was a strong predictor of surgical outcome. Furthermore, numerous factors affect the postoperative outcomes of patients with CSM. The prognostic factors of outcome after undergoing expansive laminoplasty to treat CSM have been identified as age [37], symptom duration, comorbidities [38], congenital narrow spinal canal [29], myelopathy severity, myelomalacia observed in MRI scans [11], and sagittal cervical alignment [15,30]. Although each factor is essential for determining the prognosis of postoperative neurological improvement, no reports have described the factor most critical for predicting the surgical outcome. In the current study, increased age, depression disorder, and myelomalacia significantly and negatively affected the surgical outcome; however, further observation and follow-up is necessary.
In this study, the surgical outcomes of laminoplasty in patients with CSM were observed for an average of 25 months. No further deterioration was observed in the clinical and radiographical follow-up results after 12 months postoperation, indicating that surgical outcomes stabilize at month 12 . Thus, only data until month 12 are presented in this study. No progression of cervical myelopathy was observed among the patients. Only three patients demonstrated evident C5 palsy (MMT score $<3$ ), and this incidence $(2.8 \%)$ was relatively low compared with that of the average values (4.7\%) that have been reported in the literature $[19,20]$. Substantial posterior shifts of the spinal cord caused by excessive expansion can readily cause the development of C5 palsy [20]. This problem could be solved by placing a medial trough as a hinge and lowering the lamina opening to minimize excessive posterior cord drift.

Five patients demonstrated poor wound healing and received prolonged or second admission to undergo debridement and antibiotic treatment. All five patients exhibited Type II DM, which yields elevated wound complication rates; thus, we consulted with metabolism doctors to control patient glucose levels by using medication and diet controls. No subsequent deep tissue infection or osteomyelitis was observed. To prevent severe complications, urgent debridement and antibiotic treatment followed by in-patient wound observation should be administered to those who exhibit poor wound healing. No cases of screw loosening occurred, and we carefully verified the screw purchasing quality intraoperatively. Thick screws are chosen or the fixing of original screws to the other bone area of the opened laminae is warranted when the screws tend to loosen.

Ten patients had developed kyphosis at 3 months postoperation. The reasons for the kyphotic change may be related to disrupted dorsal ligamentous structures, compromised extensor musculature, and the force from the less mobile segment; these factors may be related to late rehabilitation. Several modified surgical techniques have been developed to reduce postoperative neck pain after laminoplasty [39]. Early postoperative ROM exercises and a decreased period of neck collar protection may improve postoperative neck pain and decrease the loss of cervical ROM [40]. In the current study, the average level of moderate to severe postoperative neck pain was $42 \%$ at 3 months postoperation; this rate was similar to those reported in previous studies $[17,18]$. The modifications that we implemented required decreased surgical dissection after the careful repair of the semispinalis cervicis muscle and nuchal ligament. In addition, the patients were provided early education regarding neck extension exercise to be practiced while wearing their protective neck collars. After March 2011, we implemented additional changes to our surgical 
procedures to minimize surgical trauma and reduce postoperative neck pain.

Based on the literature, the mean surgical time for various kinds of laminoplasty was approximately 50-230 min and the mean intraoperative blood loss was $52-370 \mathrm{ml}$ $[26,41,42]$. To conduct the current procedure, we used a scalp clip applier to safely and gently open the laminae, subsequently fixing the opened laminae with self-bent titanium miniplates. The mean blood loss amount and average surgical times were within the normal ranges and the surgical outcomes were satisfactory. We suggest that surgical techniques be chosen based on the experience of the surgeon with specific procedures.

Regarding potential study limitations, the total followup period was short and no control group was formed. In addition, no patient-based outcome measures, such as the short-form health survey or subjective satisfaction measure, were assessed in this study. The current results demonstrated that conducting EOLP with miniplates is a safe and effective procedure; furthermore, it yields a low complication rate and can stop the progressive loss of or restore neurological function. The recovery rate in this study was more than $75 \%$, which is comparable to that in previous reports $[43,44]$. No patients in this study required revision to correct fixation failure, which could have caused lamina closure. This demonstrates that internal fixation facilitates maintaining the position of the lamina.

\section{Conclusion}

EOLP secured with titanium miniplates without bone grafting appears to be a safe and effective method of arresting the progression of myelopathy; this method yields marked functional improvement in most patients with CSM.

\section{Competing interests}

The authors declare that they have no competing interests.

\section{Authors' contributions}

All authors had substantial contributions to the conception and design of the study and giving of the final approval to the manuscript. KTY, TCY, and WTW participated in the data acquisition. KTY and TCY were responsible for the data interpretation and writing of the manuscript. WTW and RPL were responsible for the manuscript modification and concept clarification. All authors have read and approved the final manuscript.

\section{Author details}

${ }^{1}$ Institute of Medical Sciences, Tzu Chi University, No. 701, Zhongyang Rd. Sec. 3, Hualien 97004, Taiwan. ²Department of Orthopedics, Hualien Tzu Chi Hospital, Buddhist Tzu Chi Medical Foundation, Hualien 970, Taiwan. ${ }^{3}$ School of Medicine, Tzu Chi University, Hualien 97004, Taiwan.

Received: 19 November 2013 Accepted: 16 June 2014

Published: 21 August 2014

\section{References}

1. Matsumoto M, Fujimura Y, Suzuki N, Nishi Y, Nakamura M, Yabe Y, Shiga H: MRI of cervical intervertebral discs in asymptomatic subjects. J Bone Joint Surg (Br) 1998, 80:19-24.

2. Tracy JA, Bartleson JD: Cervical spondylotic myelopathy. Neurologist 2010, 16:176-187. doi:10.1097/NRL.0b013e3181da3a29.
3. Baron EM, Young WF: Cervical spondylotic myelopathy: a brief review of its pathophysiology, clinical course, and diagnosis. Neurosurgery 2007, 60:S35-S41.

4. Epstein JA, Carras R, Hyman RA, Costa S: Cervical myelopathy caused by developmental stenosis of the spinal canal. J Neurosurg 1979, 51:362-367.

5. Orr RD, Zdeblick TA: Cervical spondylotic myelopathy: approaches to surgical treatment. Clin Orthop Relat Res 1999, 359:58-66.

6. Matz PG, Anderson PA, Holly LT, Groff MW, Heary RF, Kaiser MG, Mummaneni PV, Ryken TC, Choudhri TF, Vresilovic EJ, Resnick DK, Joint Section on Disorders of the Spine and Peripheral Nerves of the American Association of Neurological Surgeons and Congress of Neurological Surgeons: The natural history of cervical spondylotic myelopathy. J Neurosurg Spine 2009, 11:104-111.

7. Hale JJ, Gruson Kl, Spivak JM: Laminoplasty: a review of its role in compressive cervical myelopathy. Spine J 2006, 6:289S-98S.

8. Liu T, Yang HL, Xu YZ, Qi RF, Guan HQ: ACDF with the PCB cage-plate system versus laminoplasty for multilevel cervical spondylotic myelopathy. J Spinal Disord Tech 2011, 24:213-220. doi:10.1097/BSD.0b013e3181e9f294.

9. Hirabayashi K, Toyama Y, Chiba K: Expansive laminoplasty for myelopathy in ossification of the longitudinal ligament. Clin Orthop Relat Res 1999, 359:35-48.

10. Steinmetz MP, Resnick DK: Cervical laminoplasty. Spine J 2006, 6:274S-281S.

11. Kawai S, Sunago K, Doi K, Saika M, Taguchi T: Cervical laminoplasty (Hattori's method): procedure and follow-up results. Spine (Phila Pa 1976) 1988, 13:1245-1250.

12. Puttlitz CM, Deviren V, Smith JA, Kleinstueck FS, Tran QN, Thurlow RW, Eisele P, Lotz JC: Biomechanics of cervical laminoplasty: kinetic studies comparing different surgical techniques, temporal effects and the degree of level involvement. Eur Spine J 2004, 13:213-221.

13. Nowinski GP, Visarius H, Nolte LP, Herkowitz HN: A biomechanical comparison of cervical laminaplasty and cervical laminectomy with progressive facetectomy. Spine (Phila Pa 1976) 1993, 18:1995-2004.

14. Herkowitz HN: Cervical laminaplasty: its role in the treatment of cervical radiculopathy. J Spinal Disord 1988, 1:179-188.

15. Herkowitz HN: A comparison of anterior cervical fusion, cervical laminectomy, and cervical laminoplasty for the surgical management of multiple level spondylotic radiculopathy. Spine (Phila Pa 1976) 1988, 13:774-780.

16. Satomi K, Ogawa J, Ishii Y, Hirabayashi K: Short-term complications and long-term results of expansive open-door laminoplasty for cervical stenotic myelopathy. Spine J 2001, 1:26-30.

17. Cho CB, Chough CK, Oh JY, Park HK, Lee KJ, Rha HK: Axial neck pain after cervical laminoplasty. J Korean Neurosurg Soc 2010, 47:107-111.

18. Hosono N, Sakaura H, Mukai Y, Fujii R, Yoshikawa H: C3-6 laminoplasty takes over C3-7 laminoplasty with significantly lower incidence of axial neck pain. Eur Spine J 2006, 15:1375-1379.

19. Sakaura H, Hosono N, Mukai Y, Ishii T, Yoshikawa H: C5 palsy after decompression surgery for cervical myelopathy: review of the literature. Spine (Phila Pa 1976) 2003, 28:2447-2451.

20. Imagama S, Matsuyama Y, Yukawa Y, Kawakami N, Kamiya M, Kanemura T, Ishiguro N, Nagoya Spine Group: C5 palsy after cervical laminoplasty: a multicentre study. J Bone Joint Surg (Br) 2010, 92:393-400.

21. Matsumoto M, Watanabe K, Tsuji T, Ishii K, Takaishi H, Nakamura M, Toyama Y, Chiba K: Risk factors for closure of lamina after open-door laminoplasty. J Neurosurg Spine 2008, 9:530-537. doi:10.3171/SPI.2008.4.08176.

22. Matsumoto M, Watanabe K, Hosogane N, Tsuji T, Ishii K, Nakamura M, Chiba K, Toyama Y: Impact of lamina closure on long-term outcomes of opendoor laminoplasty in patients with cervical myelopathy: minimum 5year follow-up study. Spine (Phila Pa 1976) 2012, 37:1288-1291. doi:10.1097/BRS.0b013e3182498434.

23. O'Brien MF, Peterson D, Casey AT, Crockard HA: A novel technique for laminoplasty augmentation of spinal canal area using titanium miniplate stabilization: a computerized morphometric analysis. Spine (Phila Pa 1976) 1996, 21:474-483. discussion 484.

24. Fujibayashi S, Neo M, Yoshida M, Miyata M, Takemoto M, Nakamura T: Neck muscle strength before and after cervical laminoplasty: relation to axial symptoms. J Spinal Disord Tech 2010, 23:197-202. doi:10.1097/BSD.0b013e3181a1a73e.

25. Hirabayashi K, Miyakawa J, Satomi K, Maruyama T, Wakano K: Operative results and postoperative progression of ossification among patients with ossification of cervical posterior longitudinal ligament. Spine (Phila Pa 1976) 1981, 6:354-364. 
26. Lee DG, Lee SH, Park SJ, Kim ES, Chung SS, Lee CS, Eoh W: Comparison of surgical outcomes after cervical laminoplasty: open-door technique versus french-door technique. J Spinal Disord Tech 2013, 26:E198-E203. doi:10.1097/BSD.0b013e31828bb296.

27. Pavlov H, Torg JS, Robie B, Jahre C: Cervical spinal stenosis: determination with vertebral body ratio method. Radiology 1987, 164:771-775.

28. Tashjian VS, Kohan E, MCArthur DL, Holly LT: The relationship between preoperative cervical alignment and postoperative spinal cord drift after decompressive laminectomy and arthrodesis for cervical spondylotic myelopathy. Surg Neurol 2009, 72:112-117. doi:10.1016/j.surneu.2009.02.024.

29. Sieh KM, Leung SM, Lam JS, Cheung KY, Fung KY: The use of average Pavlov ratio to predict the risk of post operative upper limb palsy after posterior cervical decompression. J Orthop Surg Res 2009, 4:24. doi:10.1186/1749-799X-4-24.

30. Ahn JS, Lee JK, Kim BK: Prognostic factors that affect the surgical outcome of the laminoplasty in cervical spondylotic myelopathy. Clin Orthop Surg 2010, 2:98-104. doi:10.4055/cios.2010.2.2.98. Epub 2010 May 4.

31. Hirabayashi K, Satomi K: Operative procedure and results of expansive open-door laminoplasty. Spine (Phila Pa 1976) 1988, 13:870-876.

32. Eskander MS, Balsis SM, Balinger C, Howard CM, Lewing NW, Eskander JP, Aubin ME, Lange J, Eck J, Connolly PJ, Jenis LG: The association between preoperative spinal cord rotation and postoperative $C 5$ nerve palsy. J Bone Joint Surg Am 2012, 94:1605-1609.

33. Heller JG, Edwards CC 2nd, Murakami H, Rodts GE: Laminoplasty versus laminectomy and fusion for multilevel cervical myelopathy: an independent matched cohort analysis. Spine (Phila Pa 1976) 2001, 26:1330-1336.

34. Woods Bl, Hohl J, Lee J, Donaldson W 3rd, Kang J: Laminoplasty versus laminectomy and fusion for multilevel cervical spondylotic myelopathy. Clin Orthop Relat Res 2011, 469:688-695. doi:10.1007/s11999-010-1653-5.

35. Ratliff JK, Cooper PR: Cervical laminoplasty: a critical review. J Neurosurg 2003, 98:230-238.

36. Hyun SJ, Rhim SC, Roh SW, Kang SH, Riew KD: The time course of range of motion loss after cervical laminoplasty: a prospective study with minimum two-year follow-up. Spine (Phila Pa 1976) 2009, 34:1134-1139. doi:10.1097/BRS.0b013e31819c389b.

37. Matsuda Y, Shibata T, Oki S, Kawatani Y, Mashima N, Oishi H: Outcomes of surgical treatment for cervical myelopathy in patients more than 75 years of age. Spine (Phila Pa 1976) 1999, 24:529-534.

38. Kawaguchi Y, Matsui H, Ishihara H, Gejo R, Yasuda T: Surgical outcome of cervical expansive laminoplasty in patients with diabetes mellitus. Spine (Phila Pa 1976) 2000, 25:551-555.

39. Ono A, Tonosaki Y, Numasawa T, Wada K, Yamasaki Y, Tanaka T, Kumagai G Aburakawa S, Takeuchi K, Yokoyama T, Ueyama K, Ishibashi Y, Toh S: The relationship between the anatomy of the nuchal ligament and postoperative axial pain after cervical laminoplasty: cadaver and clinical study. Spine (Phila Pa 1976) 2012, 37:E1607-E1613. doi:10.1097/BRS.0b013e318274101b.

40. Park AE, Heller JG: Cervical laminoplasty: use of a novel titanium plate to maintain canal expansion-surgical technique. J Spinal Disord Tech 2004, 17:265-271

41. Jiang JL, Li XL, Zhou XG, Lin H, Dong J: Plate-Only Open-Door Laminoplasty with Fusion for Treatment of Multilevel Degenerative Cervical Disease. J Clin Neurosci. 2012, 19:804-9.

42. Machino M, Yukawa Y, Hida T, Ito K, Nakashima H, Kanbara S, Morita D, Kato F: Can Elderly Patients Recover Adequately after Laminoplasty?: A Comparative Study of 520 Patients with Cervical Spondylotic Myelopathy. Spine (Phila Pa 1976) 2012, 37:667-71.

43. Tomita K, Kawahara N, Toribatake Y, Heller JG: Expansive midline T-saw laminoplasty (modified spinous process-splitting) for the management of cervical myelopathy. Spine (Phila Pa 1976) 1998, 23:32-37.

44. Machino M, Yukawa Y, Hida T, Ito K, Nakashima H, Kanbara S, Morita D, Kato F: Modified double-door laminoplasty in managing multilevel cervical spondylotic myelopathy: surgical outcome in 520 patients and technique description. J Spinal Disord Tech 2013, 26:135-140. doi:10.1097/BSD.0b013e31823d848b.

\section{doi:10.1186/s13018-014-0049-8}

Cite this article as: Yeh et al:: Expansive open-door laminoplasty secured with titanium miniplates is a good surgical method for multiple-level cervical stenosis. Journal of Orthopaedic Surgery and Research 2014 9:49.

\section{Submit your next manuscript to BioMed Central and take full advantage of:}

- Convenient online submission

- Thorough peer review

- No space constraints or color figure charges

- Immediate publication on acceptance

- Inclusion in PubMed, CAS, Scopus and Google Scholar

- Research which is freely available for redistribution 